\title{
AH! QUE MELODIA! DE ARTHUR SCHNITZLER
}

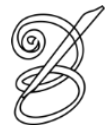 \\ Traduzido por: \\ Martha Lucía PULIDO* \\ Universidad de Antioquia, Colômbia
}

RECEBIDO EM: 08 de setembro de 2019

ACEITO EM: 30 de novembro de 2019

PUBLICADO EM: janeiro 2020

rthur Schnitzler (1862-1931), autor vienense, foi escritor de novelas, peças de
teatro, roteiros de filmes e contos. O filme De olhos bem fechados (Eyes wide shut,
1999), dirigido por Stanley Kubrick, foi baseado em Traumnovelle (1926) [Relato de um sonho] de Schnitzler. Miguel Ángel Vega Cernuda, na apresentação da sua tradução para o espanhol da novela En busca de horizontes ${ }^{1}$, afirma que: "o esqueleto que mantém toda a atividade humana que Schnitzler observa é aquele mecanismo articulado composto pelo prazer de ser, pela pulsão sexual e pelo medo do inevitável deixar de ser. Esse esqueleto é o denominador comum que reduz a multifacetada humanidade vienense da época a uns quantos tipos de homem: o esteta superficial, o político venal, o hedonista amoral, o jornalista prostituído ou o lutador por ira" ${ }^{2}$. Um desses tipos de homem é o personagem da história que apresentamos nesta tradução.

\section{AH! QUE MELODIA! (WELCH EINE MELODIE)}

Na janela de uma casa de campo estava sentado um menino - não parece um conto de fadas? -, de vez em quando olhava para a floresta que se estendia diante de seus olhos até a entrada da cidade. A quietude era tal que nem um ramo de uma árvore em toda a extensão parecia se mover. $\mathrm{O}$ ar azul profundo de uma tarde de verão sonolenta produzia um calor esmagador que pesava sobre a terra. Brincando com uma inspiração desordenada, a criança desenhava notas sobre uma partitura que tinha na frente dela no balaústre da janela. Ausente, 
colocava notas sem ordem no papel, acrescentando depois, com uma espécie de zelo infantil, medindo e sustentando as barras. Quando completou uma linha, considerou com um sorriso satisfeito o resultado de seu jogo, sem ter a menor noção do que tinha escrito. Depois de um momento, cansado pelo calor esmagador que atingia a janela aberta, abandonou o lápis e fícou ali, com os olhos perdidos no vazio, sonhando de olhos abertos. Uma brisa, uma brisa muito leve surgiu... e a partitura voou. O menino a seguiu com o olhar sem parecer alarmado, viu o papel agarrar-se aos galhos e depois descer em um lento deslize pelo caminho estreito ao final do qual se deteve. Sem maiores preocupações, voltou para o seu quarto, sentou-se ao piano e começou a praticar escalas.

Alguns momentos depois, um jovem - cuja aparência revelava, até mesmo para um observador superficial, o artista iniciante ou pelo menos o fervoroso amador de arte avançava pelo caminho. Ele caminhava cantando qualquer música, quando seu olhar se deteve sobre a folha de papel arrastada até lá pelo vento e cujo lado escrito, exposto ao exterior, se apresentava a sua vista. Ele a pegou rapidamente do chão e a considerou com curiosidade:

- Olha só! - exclamou com jocosidade. - Parece que nesta floresta, longe da 252 cidade, eu não sou o único compositor! Caramba! Que lindas pernas de mosca meu desconhecido colega rabiscou ali, à sombra dessas árvores!

E, tentando identificar a melodia, começou a cantarolá-la, decifrando lentamente os fragmentos que estavam escondidos na página do pequeno caderno de música...

— Não é ruim, não! Não há dúvida... há algo aqui. E para alguém permitir-se descartar algo assim, deve ter muitas ideias na cabeça... Meu Deus, se eu tivesse ideias assim, eu não as deixaria abandonadas na floresta!

E continuou cantarolando, dessa vez ininterruptamente, a melodia criada com tão linda inconsciência pela criança; então, sacudindo a cabeça, exclamou:

- Eis, uma coisa boa e muito oportuna! Algo para dedicar a uma jovem! Algo para Annette!

E ele correu para ver sua amada, para ver Annette. Aquela doce e adorável garota, que era para sua mãe, uma pobre viúva, a única alegria e felicidade. Seu rosto respirava pura inocência e o jovem artista sentia por ela um amor ardente e apaixonado, do qual a casta alma da moça ainda não tinha percebido a verdadeira profundidade. Ali estava ele, entrando no quarto onde a menina se encontrava sozinha, pois a mãe tinha saído para visitar uma família. Ele a cumprimentou distraidamente, quase rapidamente, depois sentou-se ao piano e começou a improvisar. Ela se sentou ao seu lado, prestando atenção e olhando para ele silenciosamente 
com seus olhos suaves, calmos e serenos. No entanto, a expressão em seu rosto mudou assim que ela começou a ouvir os primeiros acordes. Ela prestou mais atenção ainda, um leve rubor percorreu suas bochechas pálidas, e em seus olhos, que ainda estavam claros e sérios, um estranho brilho aquoso apareceu. Em suas feições, percebia-se uma emoção intensa, como se estivesse sendo acariciada, possuída por algo infinitamente profundo, ela murmurou:

- Ah! Que melodia!

O jovem artista continuou a improvisação sobre o tema que um azar o fez encontrar na floresta. Seus dedos faziam nascer das teclas como por encantamento, toda uma série de variações magníficas de cujo seio sempre se elevava a maravilhosa e única melodia, mais profunda e mais bela a cada aparição! Ah! Que melodia! Apenas um gênio poderia ter essas ideias! Somente um gênio poderia, com um motivo tão breve e simples, exercer tanta força no ouvinte, transportando-o para longe do mundo para imergi-lo no mais profundo e sublime encanto...!

Ah! Que melodia! E enquanto o jovem artista tocava a peça pela última vez e a desenvolvia, ela desmaiava lentamente, depois estremecia-se em longos suspiros, no ar que parecia sorver toda aquela harmonia, como se quisesse recomeçar.

Encantada e como perdida em um sonho celestial, a jovem permaneceu imóvel por alguns instantes, depois seus olhos brilhantes se elevaram para o amado e se fixaram nele. Abraçou-o com uma expressão de admiração apaixonada e sem reservas. Ela ainda não tinha pronunciado uma palavra, mas já estava deitada a seus pés e, tomando as mãos do jovem surpreso, ela as levou à boca, enchendo-as de beijos ardentes. Ele se inclinou para ela sem dizer nada, e então, suspirando e rindo ao mesmo tempo, ela o abraçou com um fogo que ele não conhecia nem esperava dela. Ela estava em seus braços, sua respiração o envolveu com uma doçura inebriante...

Ah! Que melodia! Foi para os dois o prelúdio de infinitas delícias...!

Claro que não se casou. Um grande artista não conclui suas aventuras mais interessantes de maneira tão trivial! Mas foi fiel por um longo tempo... alguns meses durante os quais escreveu uma peça para piano que o fez famoso.

Sim! Realmente parece um conto de fadas! Os entusiastas falavam do incrível tema desse fragmento, um crítico escreveu que "além de ter sido executado com talento, a ideia do trabalho era genial". O mundo musical e particularmente as mulheres só falavam sobre isso, não era uma peça composta por um amante, não, só o próprio amor poderia ter sido seu autor! 
Sim, também era um tema composto... particularmente para as mulheres e Annette pagou o preço, pobre Annette!

Nunca o público foi mais impaciente e mais curioso sobre um trabalho do que sobre o segundo grande trabalho de nosso compositor. E ele se fez esperar por muito tempo, enquanto aquele que todos consideravam como o feliz inventor dessa linda ideia musical, celebrada em todos os lugares e cujos méritos ficaram lisonjeados em muitos círculos, logo esqueceu sua Annette. Deitado nos braços das damas mais bonitas e elegantes da cidade... As mulheres, na verdade, são imensamente generosas com os artistas, porque gostam de devolver os prazeres que lhes foram oferecidos.

Sua peça para piano tornou-se popular. Um arranjo para orquestra e cordas foi feito com o tema e deu a volta nas salas de concerto do mundo..., mas, quando o compositor iria escrever um novo trabalho? A espera foi em vão e o público começou a se sentir desapontado. Aos poucos dele somente se conheceria esse tema magnífico e não demorou muito para que seu nome caísse no esquecimento.

Então, depois de cerca de um ano, uma história percorreu a cidade: aquele que tinha 254 sido tão celebrado até recentemente tinha cometido suicídio com um tiro no coração. O boato foi confirmado. O jovem artista estava morto! Por que esse suicídio? Ninguém, entre os que o conheciam, encontrava uma razão. Quanto a saber se uma grande obra musical tinha desaparecido com ele, ainda estava por decidir-se.

Tudo parece indicar que ele teve, de um momento para o outro, consciência, em uma hora escura, de dever sua própria celebridade mais a um estranho azar do que a suas próprias habilidades, à feliz ideia de - só Deus saberá quem - um sonhador que perdeu uma vez na floresta uma página cheia de notas. Talvez ele tenha se matado por remorso, vaidade ferida, até mesmo um sentimento de ciúme em relação ao inventor desse tema. Fosse o que fosse, ele havia deixado este mundo, onde não tinha mais nada a fazer no meio daqueles que o adoravam.

E o verdadeiro autor da melodia, embora inconsciente? - Não diríamos que é uma história... uma história ridícula, entristecedora e surpreendente ao mesmo tempo?

O menino tentou tocar o famoso fragmento e, como não conseguia, pediu a seu professor de piano para fazê-lo. Ele pôs-se a ouvir com solenidade, a cabeça apoiada na mão, aquela música maravilhosa... que teve o mesmo efeito sobre ele do que sobre todos os que tinham se encantado com a beleza do tema. O mundo novo e desconhecido que surgiu daí se 
apoderou dele como a premonição de uma maravilha fantástica e distante, que podemos sentir profundamente, mas que é impossível concebermos...

Era a música das esferas, que o subjugava com seu esplendor... Ah! Que melodia!

Nota da Tradutora: A tradução desse conto tomou como ponto de partida a versão francesa $^{3}$ tendo sempre o texto alemão ${ }^{4}$ ao lado. O texto final em espanhol foi lido pelo professor Miguel Ángel Vega Cernuda, para quem vão os meus agradecimentos. A escrita de Schnitzler é ágil, intensa, comovente e inesperada. A maneira como o tradutor francês captou as nuances da língua alemã foi determinante para traduzir para ao português os gestos, os silêncios, as paixões e os desencadeamentos da história no caminho para o desastroso fim. Schnitzler é um mestre da história curta, consegue transmitir os fracassos humanos com um sentido estético no qual a elegância, nesse caso das notas musicais, se alterna com as extravagâncias do personagem que o levam até a sua queda, sem agredir a suscetibilidade do leitor.

\footnotetext{
* Martha Lucía PULIDO Correa - Doutora em Ciencias literarias y humanas (1996), mestre em Literatura e civilização francesa e literatura comparada (1991). Especialista em Letras (1990) pela Université Paris-Est Créteil Val-de-Marne, França. Graduada em Licenciatura Espanhol-Inglês (1989) pela Universidad Pontificia Bolivariana, Colômbia. É professora-pesquisadora na Universidad de Antioquia, Colômbia, e professorapesquisadora no Programa de Pós-Graduação em Estudos da Tradução da Universidade Federal de Santa Catarina (PGET/UFSC). Antioquia, Colombia.

Currículo acadêmico: http://lattes.cnpq.br/6362075287830106

ORCID: https://orcid.org/0000-0002-1797-0703

E-mail: martha.pulido@udea.edu.co; marthaluciapulido@gmail.com

${ }^{1}$ SCHNITZLER, Arthur. En busca de Horizontes. Editado e traduzido por: Miguel Ángel Vega. Madri: Cátedra, 1999. Traduzido de: Der Weg ins Freie.

2 VEGA, Miguel Ángel. El efecto Viena, el efecto Balzac y el efecto Freud. In: Schnitzler, Arthur. En busca de Horizontes. Editado e traduzido por: Miguel Ángel Vega. Madri: Cátedra, 1999. p. 16-17.

${ }^{3}$ SCHNITLZER, Arthur. Ah, quelle melodie! In: SCHNITLZER, Arthur. Le dernier adieu. Traduzido do alemão por: Pierre Gallisaires. Paris: Union Générale d'Éditions, 1961. p. 13-17.

${ }^{4}$ SCHNITZLER, Arthur. Welch eine Melodie. Spiegel. Projekt Gutenberg - DE. Disponível em: https://gutenberg.spiegel.de/buch/welch-eine-melodie-5354/1. Acesso em: 2 jan. 2020.
} 